\title{
The Preparation and Characterization of Alginate-Chitosan Membranes as Solid Support for BTB and Urease Entrapment
}

\author{
Dhony Hermanto ${ }^{1,2^{*}}$, Mudasir Mudasir ${ }^{2}$, Dwi Siswanta ${ }^{2}$, Bambang Kuswandi ${ }^{3}$, Nurul Ismillayli ${ }^{1}$ \\ 'Department of Chemistry, Faculty of Mathematics and Natural Sciences, University of Mataram, Mataram \\ 83125, Indonesia \\ ${ }^{2}$ Department of Chemistry, Faculty of Mathematics and Natural Sciences, University Gadjah Mada, \\ Yogyakarta 55281, Indonesia \\ ${ }^{3}$ Chemo and Biosensor Group, Faculty of Pharmacy, University of Jember, Jember 68121, Indonesia
}

*Corresponding author email: dhony.hermanto@gmail.com

Received April 15, 2019; Accepted February 27, 2020; Available online March 15, 2020

\begin{abstract}
A study of alginate-chitosan membrane synthesize was done. The membrane was prepared by mixing alginate and chitosan hydrosols (1:1 in mass ratio) at $\mathrm{pH}$ approximately 5.28. Then it was applied for matrix immobilization of urease and bromothymol blue (BTB) by entrapment technique. The physical, chemical, thermal properties of alginatechitosan membrane and their impact on immobilized urease activity were investigated. The polymer products were characterized by Fourier Transform Infrared Spectroscopy (FTIR), X-Ray Diffraction (XRD), Thermogravimetric Analysis (TGA), Differential Thermal Analysis (DTA), and Scanning Electron Microscopy (SEM). It's showed that alginate-chitosan membrane was formed by electrostatic interaction. The obtained membran has better mechanical properties than original alginat and chitosan membranes. The immobilization urease into alginate-chitosan membrane retained the catalytic activity of the enzyme, as confirmed by color change of BTB indicator after membrane was immersed in substrate solution (urea). Therefore, alginate-chitosan membrane has good characteristics as matrix of enzyme immobilization.
\end{abstract}

Keywords: alginate-chitosan, membrane, preparation, characterization, application

\section{INTRODUCTION}

The increased interest of scientific and industrial in polyion complex (PIC) membranes implicate in increasing number of its articles. PIC have been extensively studied in the last years and used for technological applications in enzyme immobilization matrices. Formerly, the matrices were only considered as supporting solid of biomolecules. The material has important influence to the activity and the stability of an enzyme immobilized, it has significant theoretical meaning and practical value to probe new materials and methods. Recently, significant research efforts have been concentrated on preparing chemically PIC membranes to produce immobilized enzyme with high-performance characteristics. The formation of PIC may strongly affect the polymer solubility, rheology, conductivity, and turbidity of polymer solutions. Similarly, the mechanical properties, permeability, and electrical conductivity of the polymeric systems may be greatly affected by complex formation (Wang et al., 2015).

Polymers that contain a net negative or positive charge at near neutral $\mathrm{pH}$ are called polyions. Particularly, PIC is an association complex formed between polymers that have polyions with opposite charges because of the electrostatic interaction between the opposite charged ionic polymers (Verma \& Verma, 2013). Generally, poly-acids and weak poly-bases are used to synthesize interpolymer complexes. The synthetic PIC dominated the composite matrices, but recently, their popularity has decreased due to their nonenvironmental compatibility and degradability. For example synthetic PIC such as Poly(allylamine) (PAA), poly-L-lysine (PLL), poly-L-arginine (PLA), polyL-histidine (PLH), and polyethylene imine (PEI) contain the amine groups, which are ionized in neutral to alkaline media (usually used as polycations), whereas poly(styrenesulfonate) (PSS), poly(vinyl sulfonate) (PVS), poly(acrylic acid) (PAC), poly(maleic acid) (PMA) contain the carboxylic or sulfonic groups, which are ionized in neutral to alkaline media (usually used as polyanions) (Patwekar et al., 2016; Yabuki, 2011). Biopolymer such as alginate and chitosan has replaced traditional synthetic PIC.

As biopolymers that produced from natural substances, alginate and chitosan have been applied in polymer networks (Mohy Eldin et al., 2017). The combination of alginate and chitosan via ionic interaction between carboxylate moieties on alginate 
and protonated amines on chitosan to form PIC in the form of membrane, bead (Segale, Giovannelli, Mannina, \& Pattarino, 2016), microcapsule (Ghaffarian, Pérez-herrero, Oh, Raghavan, \& Muro, 2016; Ren, Zhang, Guo, Han, \& Huo, 2016), fiber (Jiang et al., 2014), scaffold (Han, Zhou, Yin, Yang, \& Nie, 2010; Xu et al., 2019) and layer by layer (Wang et al., 2014) has been investigated widely. Previous method usually involved mixing the components first and then fabricating PIC materials. For example, Kumbhar and Pawar (2017) prepared chitosan-alginate PIC membrane as biomaterial scaffold in tissue engineering, due to their nontoxicity, biodegradability, and biocompatibility. In this work, mixing of alginate and chitosan polymers is intended to overcome previous weakness and combine good characteristics of both polymer. PIC formation is expected reduce tendency of swelling, improve specific properties such as structural thermal strength, mechanical stability, biocompatibility and biodegradability, hence suitable as matrices for enzyme immobilization. In addition, enzyme immobilization onto PIC maintained higher activities than free enzyme as well as they were stable (Jana ef al., 2015; Yabuki, 2011).

Under the right conditions and ratios, alginate has carboxyl group that can interact with the amino group of chitosan (Kulig, Zimoch-Korzycka, Jarmoluk, \& Marycz, 2016) and its ionic interactions are the main interactions inside the network of polyion membrane. Membrane does not need to use chemical cross-linking agents for electrostatic interaction between oppositely charged polyion, which can reduce the possible toxicity and other undesirable effects of the reagents (Jiang et al., 2014). In contrast to previous methods using crosslinkers in the formation of alginate-chitosan membrane, in this study hydrosol algnate was directly interacted with chitosan hydrosol. The use of crosslinker causes the denser pore which will affect the enzyme activity due to the enzyme's space limitations when undergoing conformational changes and the possible interaction of the enzyme with the crosslinker. Comparing with the constituent polymers, the alginate-chitosan has advantages when applied as immobilized biomaterial. Employing polyion membrane for biosensing systems could reject disturbing signal, implicate in decreasing interfering current and lowering limit of detection by increasing ratio of signal-to-noise (Signal/Noise) (Yabuki, 2011). For these reasons, alginate-chitosan membrane is potentially attractive materials for applications in biotechnology. By considering above mentioned excellent outcomes from processing, properties and applications of alginate-chitosan membrane, this work was undertaken to investigate physical, chemical and thermal properties of alginate-chitosan membrane and their impact on urease activity when they are used as immobilization matrix for further application.

\section{EXPERIMENTAL SECTION \\ Materials}

The urease used for preparing the biosensor was E.C. 3.5.1.5. from jack beans (Type III, U1500) 272 $\mathrm{u} / \mathrm{g}$ was stored at $4{ }^{\circ} \mathrm{C}, \mathrm{Na}$-alginate (was isolated from brown algae. 300-400 cp) and chitosan (was isolated from crab shell, 95\% deacetylated) were obtained from Sigma (St. Lois, USA). Hydrochloride acid (37\%), glacial acetic acid (98\%), sodium hydroxide and Bromothymol blue (BTB) were received from Merck (UK). A stock solution of urea (1000 $\mu \mathrm{g} / \mathrm{mL}$ ) was prepared in aqueous solution. Solutions were prepared with deionized water.

\section{Preparation of alginate-chitosan membrane}

The membrane was prepared by mixing two polymer solutions consist of chitosan hydrosol and alginate hydrosol, according to the method carried out by Hermanto, Kuswandi, Siswanta, \& Mudasir (2019). Chitosan hydrosol was made by dissolving chitosan $(1 \mathrm{~g})$ in distilled water $(25 \mathrm{~mL})$ by adding glacial acetic acid $(5 \mathrm{~mL})$ under the magnetic stirring conditions $(400 \mathrm{rpm})$ for $12 \mathrm{~h}$ to form a homogeneous mixture. Preparation of alginate hydrosol was conducted by alginate dispersion (1 g) in distilled water $(25 \mathrm{~mL})$ and homogenized with magnetic stirrer (400 rpm) then allowed to dissolve overnight (12h). The formed mixed polymers were the hydrosol solution.

The chitosan hidrosol was added to alginate hydrosol then both polymers (2\%) were homogenized by a homogenizer (IKA, T18, Ultra Turrax, Staufen, Germany) for $90 \mathrm{~s}$. The mixtures were poured into polypropylene beakers of $60 \mathrm{~mL}$ to make a gel membrane and then chilled for further used. The hydrosol mixture $(50 \mathrm{~mL}$ alginatechitosan) was used, the mixture was added with $2 \mathrm{~mL}$ of $32 \% \mathrm{HCl}$ and then adjusted with $\mathrm{NaOH} 10 \%(\mathrm{w} / \mathrm{v})$ to reach $\mathrm{pH}$ at 5.28 approximately. The mixture was then stirred for $\pm 4 \mathrm{~h}$ at room temperature, until homogenous. The mixture solution $(10 \mathrm{~mL})$ was poured onto $5.2 \times 5.2 \mathrm{~cm}$ Petri dish and dried for $72 \mathrm{~h}$ at $25^{\circ} \mathrm{C}$. The dried membranes were kept in a box containing silica.

\section{Determination of physical properties of alginate- chitosan membrane}

Mechanical strength measurements such as the tensile strength, percentage of elongation at break, and elasticity (modulus young) were measured using a universal testing machine (Hermanto, Mudasir, Siswanta, \& Kuswandi, 2019). The membrane samples were cut into pieces measuring $100 \mathrm{~mm} \times$ $20 \mathrm{~mm}$ and put into the autograph machine. The stress applied is measured in $\mathrm{MPa}$ while the test speed was set at $10 \mathrm{~mm} / \mathrm{min}$ and the measurements for the tensile strength, elongation at break and 
elasticity of each membrane were determined. Water absorption (swelling test) is determined using the gravimetric method. The dried membrane samples were kept in a desiccator for one week. The dried membranes were then immersed in $10 \mathrm{~mL}$ of distilled water for $1 \mathrm{~h}$. Next, the membranes were dried, and the membranes were weighed before and after immersing.

\section{Characterization of alginate-chitosan membrane}

The alginate-chitosan membrane was characterized with FTIR spectrometer to determine the fungtional groups of membrane. Functional groups of membranes were identified using FT-IR spectrometer (Perkin Elmer Co Japan), with a resolution of $4 \mathrm{~cm}^{-1}$ at wavenumbers range of 4000 $400 \mathrm{~cm}^{-1}$. IR absorption of the prepared alginatechitosan hydrogels was measured using the $\mathrm{KBr}$ pellet method at a compression pressure of 2500 $\mathrm{lb} / \mathrm{m}^{2}$ on an FT-IR spectrophotometer. Knowing the cristalinity of membrane was conducted by using a $X$ Ray diffractometer (Rigaku XRD Co Japan) with Cu $\mathrm{K} \alpha$ radiation $(1.54060 \AA)$. The dried membranes were analyzed using a thermo gravimetric analyzer (Shimadzu DTG60 Co Japan) and differential thermal analyzer (Shimadzu DTA60 Co Japan) under $\mathrm{N}_{2}$ atmosphere $\left(30 \mathrm{~mL} \mathrm{~min}{ }^{-1}\right.$ for TGA and $50 \mathrm{~mL}$ $\mathrm{min}^{-1}$ for DTA) from 30 to $300{ }^{\circ} \mathrm{C}$ (heating rate $10^{\circ} \mathrm{C}$ $\left.\mathrm{min}^{-1}\right)$. For determination of membrane surface morphology, SEM analysis was performed using scanning electron microscope (Hitachi TM-3000) with $3000 x$ magnification ( $15 \mathrm{kV}$ ). Samples were analyzed after carbon tape attached and platinum coated (Hitachi E-1045 as sputter coater ion) for 10s.

\section{Application membrane for enzyme immobilization}

The mixtures of alginate-chitosan hydrosol are used as the solid support for the urease and BTB immobilization. The mixture (alginate hydrosol and chitosan hydrosol) was then stirred for $\pm 4 \mathrm{~h}$ at room temperature, until homogenous. Afterward, $3 \mu \mathrm{L}$ of hydrosol mixture was taken and added to $1 \mu \mathrm{L}$ phosphate buffer ( $\mathrm{pH}$ 6.5). The buffered mixture was added with $3 \mu \mathrm{L}$ of urease (enzyme solution in phosphate buffer, $\mathrm{pH}$ 6.5) and $3 \mu \mathrm{L}$ of BTB (1.5 $\mathrm{mg} / \mathrm{mL}$ in ethanol). Here, phosphate buffer was used in the hydrosol process to maintain the enzyme in modified hydrosol matrix. Immediately, the hydrosol mixture $(10 \mu \mathrm{L})$ was poured into a designed circular mold (i.d $10 \mathrm{~mm}$ and $1 \mathrm{~mm}$ depth) and flattened using a magnetic stirrer $(300 \mathrm{rpm})$ for $10 \mathrm{~s}$. The membrane was stored for 5 days in the refrigerator $\left(4{ }^{\circ} \mathrm{C}\right)$ for the aging process. The formed membrane was then removed from the mold and kept in a close container at $4{ }^{\circ} \mathrm{C}$ until used.

\section{Monitoring of enzyme activity by reflactance spectrophotometer \\ Monitoring of enzyme activity was carried out by determining the formation of ammonia as a result of}

enzymatic reactions using reflectance spectrophotometer (by using an optical fiber spectroscopy, USB 2000 spectrometer, Ocean Optic, USA). Enzyme activity is proportional to the product produced. Determination of enzyme activity $(5 \mathrm{~min})$ was carried out at $\mathrm{pH} 7$ with a fixed urease concentration and the concentration of substrate (urea) was increased (5-70 mM).

\section{RESULTS AND DISCUSSION}

\section{Formation of alginate-chitosan membrane}

The mass ratio of $\mathrm{Na}$-alginate and chitosan at 1:1 was used, and it was optimum to form a good and stable membrane. This is due to the fact that at this ratio, interaction of amino group of chitosan and carboxilate group of alginate form the strongest interaction and produce a good formation polyion complex (Figure 1). In addition, the drying temperature and $\mathrm{pH}$ of the mixture also greatly affect these ionic interactions. The drying temperature of the alginate-chitosan membrane was optimum at room temperature, even though the aging time needed was longer (72 h) to make alginate-chitosan hydrogel membrane. Since it was treated at the room temperature, it produced a strong and well formation of the alginate-chitosan membrane. While, at the higher drying temperature, at $60{ }^{\circ} \mathrm{C}$ it was not produced a good formation of the alginate-chitosan as polyion complex membrane. This is due to the fact that at $60{ }^{\circ} \mathrm{C}$ weaker ionic bonds was formed, indicated by the membrane was brittle and easy to break-down.

In term of $\mathrm{pH}$, the formation of the alginatechitosan membrane occurred at $\mathrm{pH}$ of 5.28 approximately. Chitosan as a weak base polymer with intrinsic pKa 6.5, while alginate consists of carboxyl groups which can be ionized at $\mathrm{pH}$ above pKa which is 4.7 (Kulig et al., 2016). Therefore at pH 5.28 approximately the amino group of chitosan is protonated while alginate is in the negative carboxylic form. When the two hydrosols are mixed with a ratio of $1: 1$ there will be an electrostatic interaction between the cationic amino groups of chitosan and the anionic carboxyl groups of alginate as in Figure 2. Electrostatic interaction is the main interaction in the formation of alginate-chitosan membrane. Mixing alginate and chitosan hydrosol solutions which have opposite charges produces a primary complex that is arranged randomly because the interaction is Coulomb force and occurs very quickly. The next stage is the formation of a regular secondary complex, occurring due to the repetition or alignment of the polymer chain distortion of the primary complex. After drying, the membrane undergoes inter-complex aggregation due to hydrophobic or drying interactions which then produces tissue. Drying time also affects the properties of the membrane produced, in addition to the $\mathrm{pH}$ and ratio factors of chitosan and alginate. 

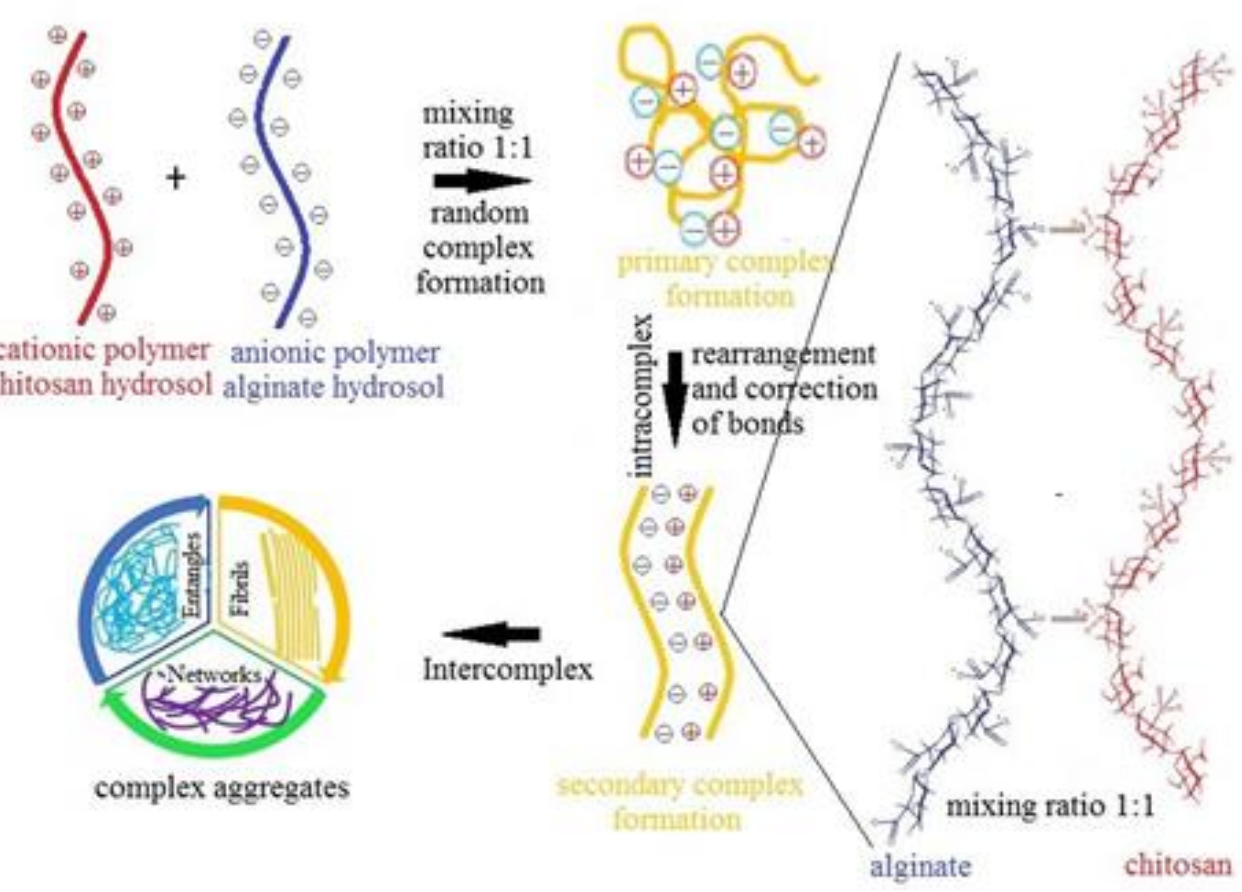

Figure 1. Schematic representation of alginate-chitosan membrane formation

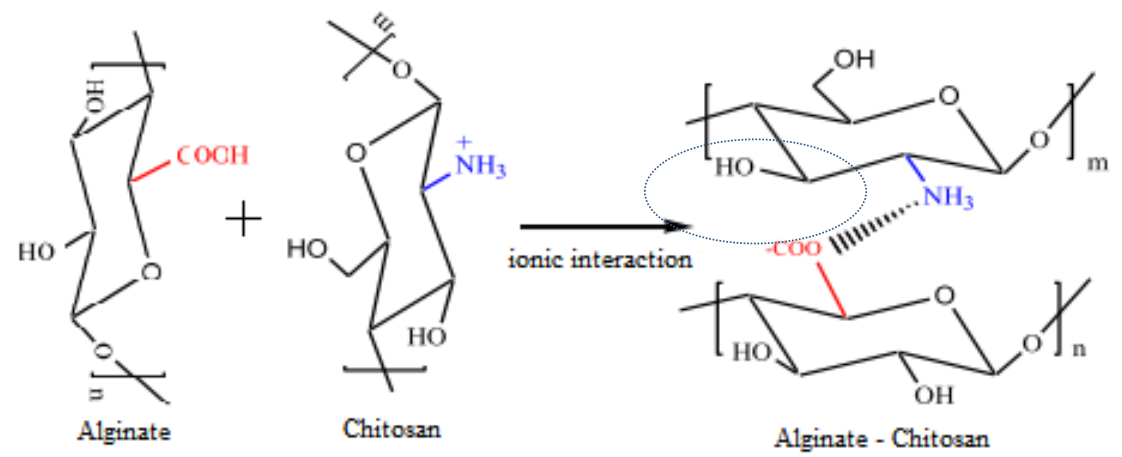

Figure 2. Scheme ionic interaction of chitosan and alginate (Mohy Eldin et al., 2017)

Adequate drying time $(72$ h) causes deeper penetration of alginate into chitosan and forms a network with suitable pores.

\section{Phisical properties alginate-chitosan membrane}

The value of tensile strength and elongation of the membrane in Table 1 shows that the alginatechitosan membrane is quite elastic because it is not easily broken. The interaction of alginate-chitosan produced a combination of mechanical strength of alginate and chitosan polymers, so that it had good mechanical strength. The interaction of these two polymers causes an increase in tensile strength and elongation of the membrane. This increase in elongation was made possible due to the membrane plasticization effect. Membrane mechanical strength gives an illustration of the physical character of the membrane regarding tensile strength and elongation. The membrane mechanical strength test is carried out for the membrane in a dry and wet state (after diffusion). The mechanical strength of the membrane in wet conditions is important to know in relation to biomaterial applications. The reduced tensile strength of the membrane in wet conditions is possible due to the formation of interactions between water and membrane. The more hydrophilic groups per unit surface area of the membrane, the stronger the water interaction with the membrane so as to provide less mechanical strength.

In Table 1, it is known that the thickness of alginate-chitosan membrane is thin membrane but has a greater modulus young value. The mechanical properties of mixed membranes are getting good properties and it is because the tight structure causes the distance between molecules in the membrane to get closer. The greater the modulus of young, the membrane has a good ability to prevent damage caused by external forces, resulting in a strong alginate-chitosan membrane. This shows that the alginate-chitosan membrane formed has a spesific structure and properties make it suitable for good supporting material. 
Table 1. The physical-mechanical properties alginate-chitosan (Hermanto et al., 2019)

\begin{tabular}{lc}
\hline The physical-mechanical properties & Value \\
\hline Thickness membrane $/ \mathrm{mm}$ & $0.021 \pm 0.92$ \\
Tensile strength (dry state) $/ \mathrm{MPa}$ & $38.04 \pm 0.66$ \\
Tensile strength (wet state) $/ \mathrm{MPa}$ & $35.12 \pm 1.88$ \\
Elongation (dry state) $/ \%$ & $8.13 \pm 0.44$ \\
Elongation (wet state) $/ \%$ & $6.06 \pm 0.67$ \\
Modulus young $/\left(\mathrm{N} / \mathrm{mm}^{2}\right.$ ) & 18.33 \\
Water absorption $/ \%$ & 104 \\
Water resistance $/ \%$ & 105 \\
\hline
\end{tabular}

Water absorption in membranes is generally similar to membrane swelling. Water absorption provides an illustration of the weight of water that can be absorbed on the membrane, while swelling provides an overview of the development of membrane volume due to trapped water in the membrane. Absorption and membrane resistance values in Table 1 show that alginate-chitosan membranes have greater water absorption and resistance. Water absorption or membrane swelling is influenced by the hydrophilic and hydrophobic balance of the membrane, cross-linking reactions, the degree of ionization and its interaction with the counter ion. Increased membrane hydrophobicity due to the formation of membrane and is expected to have greater resistance to insoluble in water. The existence of cross-linked reactions can affect the pore size in relation to the empty space between the membrane structures. Empty spaces in these membranes can trap more solutions. Due to the thermodynamic properties of polymers in different solutions, there is no theory that can predict with certainty about the nature of development. Development of alginate-chitosan membranes is probably due to the presence of $\mathrm{COO}^{-}$hydrophilic ions in the membrane. The adsorption of water on the membrane also illustrates the ease of diffusion of the substrate (urea solution) to react with urease immobilized on the alginate-chitosan membrane. The greater the water adsorption the easier the substrate diffuses on the membrane. The IR spectrum of the alginatechitosan membrane is shown in Figure 3(a), there is absorption at the wavenumber $\left(\mathrm{cm}^{-1}\right): 3429.2(\mathrm{OH}$ from alginate $/-\mathrm{NH}_{2}$ of chitosan), $2923.9\left(\mathrm{CH} \mathrm{sp}{ }^{3}\right)$, 1577.7 (COO-). The loss of the absorption band at $1157 \mathrm{~cm}^{-1}$ which characterizes the amine group shows that the chitosan amine group has been protonated and interacts with alginate carboxylic groups (Han et al., 2010). This is strengthened by the appearance of peaks in the area of $1550 \mathrm{~cm}^{-1}$ which indicates the presence of $\mathrm{NH}_{3}{ }^{+}$ions. This indicates that formation of the alginate-chitosan membrane involves the ionic interaction only. The intensity at $1398 \mathrm{~cm}^{-1}$ also showed electrostatic interaction on the alginate-chitosan membrane (1:1 in mass ratio). The presence of absorption bands mentioned above shows the presence of ionic bonds between protonated amine groups of chitosan and carboxylic groups of alginate (Hermanto et al., 2019).

The effect of alginate and chitosan interaction on membrane cristallinity was identified using X-ray diffraction pattern, as illustrated in Figure 3(b). The diffractogram of alginate-chitosan shows a wide peak as a character amorphous of alginate-chitosan membrane. Wider chitosan peak was obtained in thicker of alginate layer. It indicate that breaking of hydrogen bond in chitosan (between amino groups and hydroxyl groups) occured when PIC was formes (Kim, Lim, Jegal, \& Lee, 2000). The result is associated with electrostatic interactions of amino and carboxilate in PIC. The obtained membrane has amorphous form that conform with previous work, which preparation of alginate-chitosan composite layer through electro deposition (Cheong \& Zhitomirsky, 2008). Alginate-chitosan XRD is a characteristic of an amorphous polymer consisting of a structure of dense tissue interpenetrating a polymer chain cross-linked to one another and implying greater irregularities in the smoothing of chains in polymers (Wang et al., 2014).

The thermal degradation behavior of membrane can be represented by a thermo gravimetric analysis (TGA) thermogram, which can be used to investigate the loss of mass of membrane as a result of the decomposition process. As illustrated in Figure 3(c), a single degradation step was observed for the membrane. For the alginate-chitosan membrane, a weight loss of $18.01 \%$ was obtained at a temperature (Td) of $106.25^{\circ} \mathrm{C}$. The weight loss of the membrane is possibly due to the content of water because of the presence of a concentration of alginate, corresponding to their hydrophilicity. The differential thermal analysis (DTA) technique was employed in this research; it is generally used to investigate the thermal transition, glass transition (Tg), crystallization (Tc), and melting temperature of a polymer. From the curve achieved, the membrane exhibited endothermic peaks at $117.14{ }^{\circ} \mathrm{C}(\Delta \mathrm{Hm}=801.88 \mathrm{~J}$ $\mathrm{g}^{-1}$ ) respectively, corresponding to their melting temperatures $(\mathrm{Tm})$. The alginate and chitosan composition in the membrane resulted in a higher melting temperature due to the stronger molecular interaction of chitosan and alginate. 


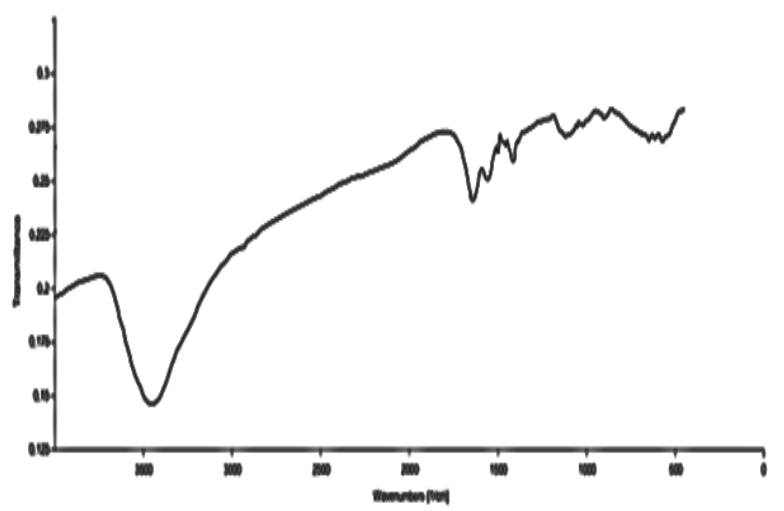

(a)

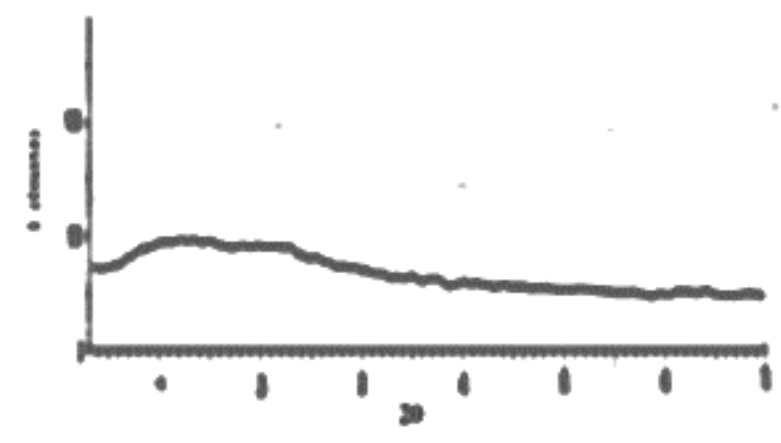

(c)

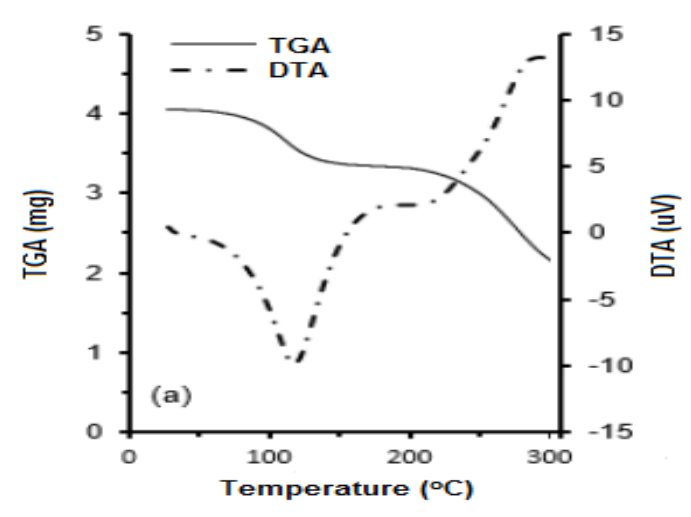

(b)

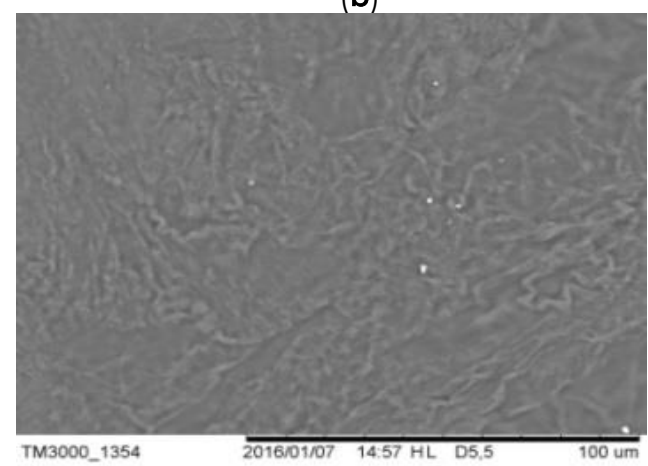

(d)

Figure 3 Characteristics of alginate-chitosan membrane (a) FTIR spectra (b) thermogram (TGA and DTA) (c) XRD pattern (d) SEM images of surface morphology

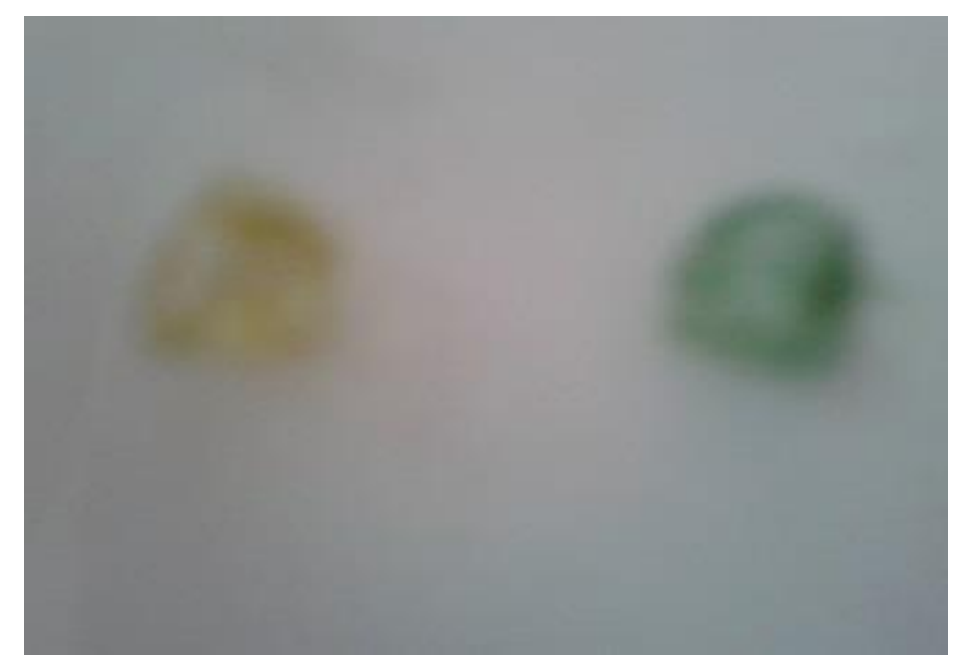

Figure 4. The BTB detected color change from yellow to green

The surface and cross-section morphology of the alginate-chitosan membrane were also studied by Scanning Electron Microscopy (SEM) as shown in Figure $3(d)$. Here, the morphology of the blended alginate-chitosan membrane was less homogenous than its native membrane. It was observed that the alginate-chitosan membrane showed irregular, fibrous structures of surface and rough cross-section morphology, which is network of electrostatic interactions of alginate and chitosan (Hermanto et al., 2019).
Immobilization of urease and BTB into alginatchitosan membrane

The success of urease immobilization into membrane was indicated by the change in color of the BTB indicator from yellow to green when reacted with urea. This color change indicates an increase in $\mathrm{pH}$ caused by the ammonia formation reaction as urea hydrolysis product catalyzed by immobilized urease. As shown in Figure 4 color change of the BTB indicator was demonstrated trapped urease in cavity of membrane. 


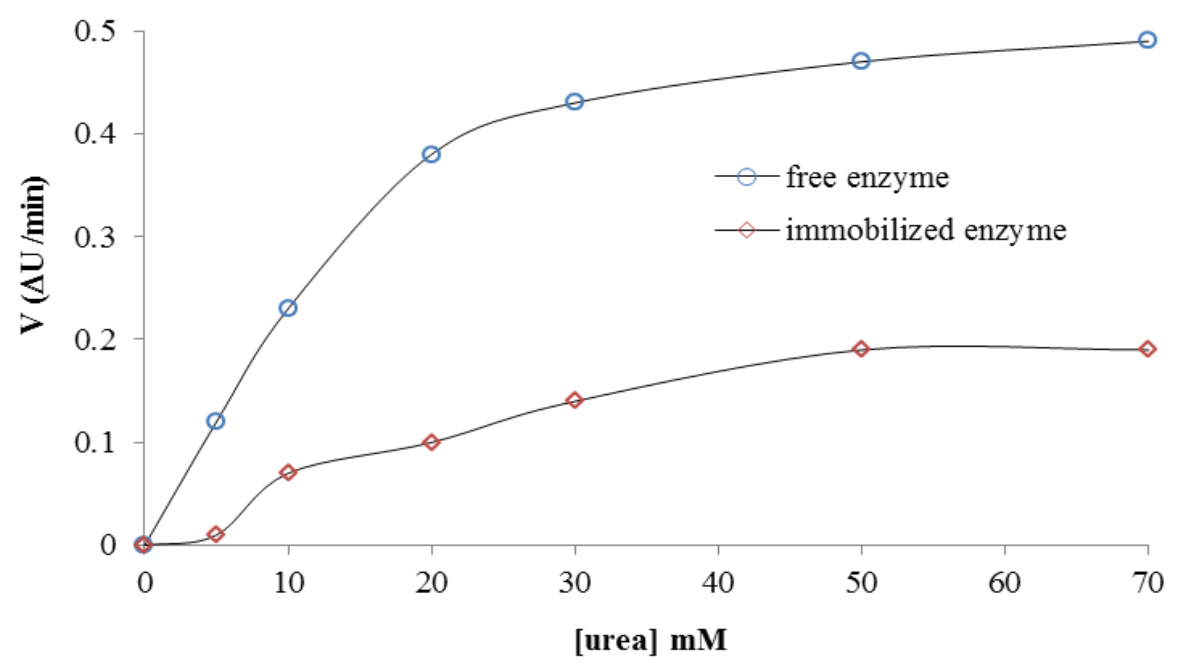

Figure 5 The change of catalytic reaction in free and immobilize urease due to changes in urea concentration

Enzyme activity is the amount of enzyme that causes the conversion of $1 \mu \mathrm{mol}$ of substrate per minute at $25{ }^{\circ} \mathrm{C}$ in optimal measurement conditions. The formation of enzyme-substrate complexes can be detected directly by the physic-chemical method, namely through changes in the absorption spectrum of the enzyme, which is characteristic when the substrate is added. In Figure 5 shows that during the addition of the initial substrate gradually the rate of reaction rises proportional to the substrate concentration, so that the rate of reaction that occurs in this condition is the reaction of the first level (first order reaction). On the addition of the substrate to excess it can be seen that the rate is constant until there is no additional reaction rate (the maximum rate is reached). In this situation all enzymes are in a complex form with the substrate so that the reaction becomes independent of the substrate concentration, and said the rate of the reaction changes to a zerolevel reaction (zero order reaction). In this case, the rate of the initial reaction is directly proportional to the concentration of the enzyme, so the actual rate limiting factor (rate-limiting factor) in this condition is the concentration of the enzyme.

Based on Figure 5, the calculated $K_{m}$ value of immobilized urease is 59.21 and the $V_{\max }$ value is $0.125 \mathrm{\Delta U} / \mathrm{min}$ while the $K_{\mathrm{m}}$ value of free urease is 40.41 and the $V_{\max }$ value is $1.095 \mathrm{\Delta U} / \mathrm{min}$. Comparison of $\mathrm{K}_{\mathrm{m}}$ and $\mathrm{V}_{\max }$ values of free and immobilized urease shows decrease in $V_{\max }$ value and increase in $K_{m}$ value. This indicates that the immobilization process using alginate-chitosan membrane with entrapment technique decreases the reaction rate of urease. It was occur because the substrate needs to diffuse first through the supporting material and then release the product, so that the enzyme response in an immobilized state was not as fast as if the enzyme was free. In addition, the motion space of enzymes immobilized when enzyme conformational changes occur is less freely when the enzymes are free in solution. Although there is decrease in urease enzyme activity, immobilization of urease in the alginate-chitosan membrane still shows good urease catalytic activity so that the alginatechitosan membrane can be used as enzyme immobilization matrix.

\section{CONCLUSIONS}

PIC membrane of alginate-chitosan as urease immobilization matrix was synthesized by mixing both hydrosol of alginate and chitosan at $\mathrm{pH}$ of 5.28. The spectra of FTIR, XRD pattern and SEM analysis indicated that alginate-chitosan membrane were formed through electrostatic interaction. Physical and thermal properties of formed alginate-chitosan membrane was better than its original polymer. Since good characteristics of membrane, BTB detected color change from yellow to green and retain activity of immobilized urease in urea solution, the alginatechitosan membran can be used as bioactive matrix of urease immobilization.

\section{ACKNOWLEDGEMENTS}

The authors are grateful to DRPM, the Minister of Research Technology and Dikti, Republic of Indonesia (Kemenristekdikti) for the research funding through doctoral dissertation research grand decree number 65F/SPP-PDDI/UN18.12/PL/2016.

\section{REFERENCES}

Cheong, M., \& Zhitomirsky, I. (2008). Electrodeposition of Alginic Acid and Composite Films. Colloids and Surfaces A: Physicochemical and Engineering Aspects, 328, 73-78.

Ghaffarian, R., Pérez-herrero, E., Oh, H., Raghavan, S. R., \& Muro, S. (2016). Chitosan-Alginate Microcapsules Provide Gastric Protection and Intestinal Release of ICAM-1-Targeting Nanocarriers, Enabling GI Targeting in Vivo. 
Advanced Functionla Materials, 26, 33823393.

Han, J., Zhou, Z., Yin, R., Yang, D., \& Nie, J. (2010). Alginate-Chitosan/Hydroxyapatite

Polyelectrolyte Complex Porous Scaffolds: Preparation and Characterization. International Journal of Biological Macromolecules, 46(2), 199-205.

Hermanto, D., Kuswandi, B., Siswanta, D., \& Mudasir. (2019). Inhibitive Determination of $\mathrm{Hg}$ (II) in Aqueous Solution Using Urease Amperometric Biosensor. Indonesian Journal of Chemistry, 19(3), 786-795.

Hermanto, D., Mudasir, Siswanta, D., \& Kuswandi, B. (2019). Synthesis of Alginate-Chitosan Polyelectrolyte Complex (PEC) Membrane and Its Physical-Mechanical Properties. Journal of Scientific and Applied Chemistry, 22(1), $11-$ 16.

Jana, S., Trivedi, M. K., Tallapragada, R. M., Branton, A., Trivedi, D., Nayak, G., \& Mishra, R. K. (2015). Characterization of Physicochemical and Thermal Properties of Chitosan and Sodium Alginate after Biofield Treatment. Pharmaceutical Analytical Acta, 6(6), 1-9.

Jiang, C., Wang, Z., Zhang, X., Zhu, X., Nie, J., \& Ma, G. (2014). Crosslinked Polyelectrolyte Complex Fiber Membrane Based on ChitosanSodium Alginate by Freeze-Drying. RSC Advances, 40(78), 41551-41560.

Kim, S. G., Lim, G. T., Jegal, J., \& Lee, K. H. (2000). Pervaporation Separation of MTBE (Methyl Tert-Butyl Ether) and Methanol Mixtures Through Polyion Complex Composite Membranes Consisting of Sodium Alginate/Chitosan. Journal of Membrane Science, 174(1), 1-15.

Kulig, D., Zimoch-Korzycka, A., Jarmoluk, A., \& Marycz, K. (2016). Study on Alginate-Chitosan Complex Formed with Different Polymers Ratio. Polymers, 8(5), 1-17.

Kumbhar, S. G., \& Pawar, S. H. (2017). SelfFunctionalized, Oppositely Charged ChitosanAlginate Scaffolds for Biomedical Applications. Biotechnology, 13(2), 1-15.

Mohy Eldin, M. S., Hashem, A. E., Tamer, T. M.,
Omer, A. M., Yossuf, M. E., \& Sabet, M. M. (2017). Development of Cross Linked Chitosan/Alginate Polyelectrolyte Proton Exchanger Membranes for Fuel Cell Applications. International Journal of Electrochemical Science, 12(5), 3840-3858.

Patwekar, S. L., Potulwar, A. P., Pedewad, S. R., Gaikwad, M. S., Khan, S. A., \& Suryawanshi, A. B. (2016). Review on Polyelectrolyte Complex as Novel Approach for Drug Delivery System. Human Journals Review Article March, 5(54), 97-109.

Ren, Z., Zhang, X., Guo, Y., Han, K., \& Huo, N. (2016). Preparation and in Vitro Delivery Performance of Chitosan-Alginate Microcapsule for $\lg$ G. Food and Agricultural Immunology, 15, 1-13.

Segale, L., Giovannelli, L., Mannina, P., \& Pattarino, F. (2016). Calcium Alginate and Calcium Alginate-Chitosan Beads Containing Celecoxib Solubilized in a Self-Emulsifying Phase. Hindawi Scientifica, 2016, 1-8.

Verma, A., \& Verma, A. (2013). Polyelectrolyte Complex-an Overview. International Journal of Pharmaceutical Sciences and Research, 4(5), 1684-1691.

Wang, X. S., Ji, Y. L., Zheng, P. Y., An, Q. F., Zhao, Q., Lee, K. R., Qian, J. W., \& Gao, C. J. (2015). Engineering Novel Polyelectrolyte Complex and Separation Performance. Journal of Materials Chemistry A: Materials for Energy and Sustainability, 3, 7296-7303.

Wang, Z., Zhang, X., Gu, J., Yang, H., Nie, J., \& Ma, G. (2014). Electrodeposition of Alginate/Chitosan Layer-by-Layer Composite Coatings on Titanium Substrates. Carbohydrate Polymers, 103(1), 38-45.

Xu, K., Ganapathy, K., Andl, T., Wang, Z., Copland, J. A., Chakrabarti, R., \& Florczyk, S. J. (2019). Biomaterials 3D Porous Chitosan-Alginate Scaffold Stiffness Promotes Diferential Responses in Prostate Cancer Cell Lines. Biomaterials, 217, 1-12.

Yabuki, S. (2011). Polyelectrolyte Complex Membranes for Immobilizing Biomolecules , and Their Applications to Bio-analysis. Analytical Sciences, 27, 695-702. 